\title{
Malignant Rectosigmoid Neoplasm
}

National Cancer Institute

\section{Source}

National Cancer Institute. Malignant Rectosigmoid Neoplasm. NCI Thesaurus. Code C7420.

A primary or metastatic malignant neoplasm that affects the rectosigmoid area.

Representative examples include carcinoma, lymphoma, and sarcoma. 